\title{
Preservation of renal function by thyroid hormone replacement in elderly persons with subclinical hypothyroidism
}

Yu Lu, Hong Guo, Dongmei Liu, Zhen Zhao

Divisions of Geriatric Endocrinology, Medical and Health Care Center, Beijing Friendship Hospital Affiliated to Capital Medical University, Beijing, China

Submitted: 27 October 2014

Accepted: 1 January 2015

Arch Med Sci 2016; 12, 4: 772-777

DOI: 10.5114/aoms.2016.60965

Copyright ๑ 2016 Termedia \& Banach

\section{Abstract}

Introduction: The treatment of subclinical hypothyroidism in elderly persons is controversial. Previous studies have shown that there are interactions between kidney and thyroid function, but data regarding interventions that target thyroid function in elderly patients are scarce. We aimed to investigate the impact of thyroid hormone therapy on the estimated glomerular filtration rate (eGFR) in elderly patients.

Material and methods: Ninety elderly patients aged $\geq 65$ years with subclinical hypothyroidism were followed for 36 months in our case-control study. The changes in the eGFR in patients with and without thyroid hormone replacement therapy were compared. The adverse effects during the treatment period were noted.

Results: The eGFR of both groups was similar at the beginning of the study $\left(43.4 \pm 6.1\right.$ vs. $\left.42.8 \pm 5.9 \mathrm{ml} / \mathrm{min} / 1.73 \mathrm{~m}^{2} ; p=0.62\right)$. With the decline in thyroid stimulating hormone levels after treatment, the eGFR of the treatment group significantly improved compared with the control group ( $45.8 \pm 4.8$ vs. $\left.35.8 \pm 5.3 \mathrm{ml} / \mathrm{min} / 1.73 \mathrm{~m}^{2} ; p<0.001\right)$; the eGFR increased rapidly over the first 6 months and then plateaued. No patients withdrew from the study, but the therapeutic dose was decreased in two patients due to angina pectoris. Conclusions: Thyroid hormone therapy preserved renal function in elderly patients. Appropriate individual treatment should be considered in elderly patients with subclinical hypothyroidism.

Key words: thyroid stimulating hormone, thyroid hormone replacement therapy, estimated glomerular filtration rate.

\section{Introduction}

Subclinical hypothyroidism, defined as elevated serum thyroid stimulating hormone (TSH) but normal free thyroxine (fT4), is common in older adults; researchers found that the prevalence of subclinical hypothyroidism was $15 \%$ in community-dwelling older adults [1]. However, the treatment is controversial because the risks are uncertain and the treatment benefits are unproven. Recently, Gopinath et al. found that increased serum TSH was associated with increased prevalence of chronic kidney disease (CKD) among older adults, independent of age, diabetes and hypertension [2]. Conversely, subclinical hypothyroidism is frequently observed in CKD patients [3]. There are interactions between kidney and thyroid function.

\author{
Corresponding author: \\ Yu Lu PhD \\ Divisions of Geriatric \\ Endocrinology \\ Medical and Health \\ Care Center \\ Beijing Friendship Hospital \\ Affiliated to Capital \\ Medical University \\ 95 Yong-an Road \\ Xi-Cheng District \\ 100050 Beijing, China \\ Phone: +861063137737 \\ E-mail: sunshine4001@ \\ 163.com
}


Patients with hypothyroidism, both overt and subclinical, are characterized by a decreased glomerular filtration rate (GFR) and renal plasma flow, resulting in increased serum creatinine [4-6]. Previous clinical studies have shown that after L-thyroxine treatment for hypothyroidism, serum creatinine is rapidly completely restored to reference range levels $[5,7,8]$. Shin et al. $[9,10]$ reported that thyroid hormone replacement therapy (THRT) preserved renal function in CKD patients with subclinical hypothyroidism.

However, the clinical implications of the age-associated changes in thyroid function and elevated TSH levels in patients with subclinical hypothyroidism are not well understood. Certain studies have demonstrated that increased TSH levels are not associated with increased or decreased mortality in elderly patients [11]; rather, increased TSH levels could be an adaptive mechanism to prevent excessive catabolism [12], but data regarding interventions that target thyroid function in elderly patients are scarce. During the 36-month follow-up, we observed the changes in renal function after THRT in elderly patients with subclinical hypothyroidism and aimed to determine whether appropriate THRT is safe and offers benefits in terms of renal function.

\section{Material and methods}

\section{Study subjects}

Patients aged $\geq 65$ years who were biochemically diagnosed with subclinical hypothyroidism were followed in our internal department from January 2010 to December 2010. All of the patients exhibited normal morphology of both kidneys. The exclusion criteria were as follows: 1 ) history of chronic glomerulonephritis, nephrotic syndrome, or advanced CKD (eGFR < $30 \mathrm{ml} / \mathrm{min} / 1.73 \mathrm{~m}^{2}$ ); 2) proteinuria or hematuria; 3) acute infection or antibiotic treatment; 4) history of thyroid dysfunction or current treatment with thyroid medication; 5) currently taking amiodarone, lithium carbonate, interferon, sex hormones or steroid hormones; and 6) malignant tumors. The study was approved by the local ethics committee.

A total of 90 patients were included in this study. Clinical data were recorded at the time of diagnosis and included age, gender, body mass index (BMI), comorbidities, biochemical indices and blood pressure. The treatment group included patients with serum TSH levels $>10 \mathrm{mIU} / \mathrm{l}$ or high thyroid peroxidase antibody (TPOAb) titers $(\geq 60 \mathrm{U} / \mathrm{ml}$ ) or symptomatic patients with TSH levels between 4.5 and $10 \mathrm{mIU} / \mathrm{l}[13,14]$; the other study participants formed the control group and did not receive any treatment for their thyroid condition.

\section{Treatment protocol and follow-up assessment}

The patients in the treatment group all received the same brand of L-thyroxine (Letrox, $50 \mu \mathrm{g}$ per pill, Berlin-Chemie AG, Berlin, Germany). These patients initially received the lowest dose $(12.5 \mu \mathrm{g} /$ day); thyroid function was assessed every 4 weeks for the first 3 months, and the Letrox dose was increased by $12.5 \mu \mathrm{g} /$ day until the TSH levels fell to the target level [14]. At this point, the patients were evaluated every 6 months for a total of 36 months. During each follow-up session, the doctors recorded patient symptoms and signs, measured biochemical indices and adjusted basic treatments. The therapeutic dose was adjusted according to the TSH levels or the clinical condition of the patient.

\section{Laboratory measurements and kidney function assessment}

Serum fT3, fT4, and TSH levels were determined by chemiluminescence assay on a Roche Cobas E601 analyzer, and the TPOAb concentration was measured using a chemiluminescent immunoassay on a Siemens ADVIA Centaur analyzer. The respective reference ranges of $\mathrm{fT} 3, \mathrm{fT} 4, \mathrm{TSH}$ and TPOAb were 3.1-6.8 pmol/l, 12-22 pmol/l, $0.27-4.20 \mathrm{mIU} / \mathrm{l}$ and $<60 \mathrm{U} / \mathrm{ml}$.

Serum creatinine ( $\mathrm{SCr}$ ) was measured via the Roche enzymatic method. The Chronic Kidney Disease Epidemiology Collaboration (CKD-EPI) equation [15] was used to calculate the estimated glomerular filtration rate (eGFR).

Females SCr $\leq 62 \mu \mathrm{mol} / \mathrm{l} \mathrm{eGFR}=144 \times(\mathrm{SCr} / 0.7)^{-0.329}$ $\times(0.993)^{\text {Age }}$

$\mathrm{SCr}>62 \mu \mathrm{mol} / \mathrm{l} \mathrm{eGFR}=144 \times(\mathrm{SCr} / 0.7)^{-1.209}$

$\times(0.993)^{\text {Age }}$

Males SCr $\leq 80 \mu \mathrm{mol} / / \mathrm{eGFR}=141 \times(\mathrm{SCr} / 0.9)^{-0.411}$ $\times(0.993)^{\text {Age }}$

$\mathrm{SCr}>80 \mu \mathrm{mol} / \mathrm{l} \mathrm{eGFR}=141 \times(\mathrm{SCr} / 0.9)^{-1.209}$

$\times(0.993)^{\text {Age }}$

\section{Statistical analysis}

Continuous variables are presented as the mean $\pm S D$, and categorical variables are presented as a number (percentage). To compare the differences between the two groups, a two-sample $t$-test or the $\chi^{2}$ test was used. Various parameters at baseline and at different intervals were compared using a paired $t$-test. Repeated measurement analysis of variance was used to analyze the eGFR and various effects. Statistical significance was defined as a 2-tailed $p$-value of less than 0.05 . All of the statistical analyses were performed using the IBM SPSS Statistics program, version 19 (IBM Corp, Armonk, NY, USA). 


\section{Results}

Clinical characteristics of both groups are shown in Table I. The mean age was $78.2 \pm 9.5$ years, and $61(67.8 \%)$ patients were male. There were no significant differences in gender, age, $\mathrm{BMI}$ or incidence of basic diseases between the two groups; however, compared with the control group, the treatment group had a higher prevalence of dyslipidemia $(p=0.07)$. High TPOAb titers were present in 12 patients, all of whom were in the treatment group.
Serum TSH levels at various time points during the follow-up period are listed in Table II. TSH levels in the treatment group were significantly decreased at 1 month (13.72 \pm 2.29 vs. $7.71 \pm 2.36$ $\mathrm{mIU} / \mathrm{l} ; p<0.01$ ), were predominantly within the target range at 6 months (13.72 \pm 2.29 vs. 4.21 $\pm 0.78 \mathrm{mlU} / \mathrm{l} ; p<0.01)$ and were maintained during the follow-up period. All of the patients in the treatment group initially received Letrox at $12.5 \mu \mathrm{g} /$ day, and the mean final replacement dose was $28.0 \mu \mathrm{g} /$ day. No patients withdrew from the

Table I. Baseline characteristics of subjects

\begin{tabular}{|c|c|c|c|}
\hline Characteristic & Treatment group & Control group & $P$-value \\
\hline Number & 42 & 48 & - \\
\hline Male sex (\%) & 66.7 & 68.8 & 0.83 \\
\hline Age [years] & $77.5 \pm 10.2$ & $79 \pm 9.2$ & 0.76 \\
\hline BMI $\left[\mathrm{kg} / \mathrm{m}^{2}\right]$ & $25.4 \pm 2.2$ & $24.6 \pm 2.5$ & 0.84 \\
\hline Diabetes mellitus (\%) & 54.8 & 54.2 & 0.96 \\
\hline Hypertension (\%) & 85.7 & 83.3 & 0.76 \\
\hline Dyslipidemia (\%) & 83.3 & 66.7 & 0.07 \\
\hline Cardiovascular disease (\%) & 47.6 & 52.1 & 0.67 \\
\hline FT3 [pmol/l] & $4.62 \pm 1.27$ & $4.85 \pm 1.42$ & 0.89 \\
\hline FT4 [pmol/l] & $16.85 \pm 2.84$ & $18.62 \pm 2.78$ & 0.88 \\
\hline $\mathrm{TSH}[\mathrm{mIU} / \mathrm{l}]$ & $13.72 \pm 2.29$ & $7.09 \pm 1.23$ & $<0.01$ \\
\hline TPOAb $\geq 60 \mathrm{IU} / \mathrm{ml}(\%)$ & 28.6 & 0 & - \\
\hline $\mathrm{SCr}[\mathrm{mg} / \mathrm{dl}]$ & $136.8 \pm 25.5$ & $136.1 \pm 23.7$ & 0.89 \\
\hline $\mathrm{eGFR}\left[\mathrm{ml} / \mathrm{min} / 1.73 \mathrm{~m}^{2}\right]$ & $43.4 \pm 6.1$ & $42.8 \pm 5.9$ & 0.62 \\
\hline
\end{tabular}

The data are presented as the mean $\pm S D$ or as the percentage. The eGFR was calculated using the CKD-EPI equation.

Table II. Changes of TSH in two groups and the therapeutic dose of Letrox

\begin{tabular}{|c|c|c|c|}
\hline \multirow[t]{2}{*}{ Time } & \multicolumn{2}{|c|}{ TSH [mIU/l] } & \multirow{2}{*}{$\begin{array}{c}\text { L-thyroxine }[\mu \mathrm{g} / \mathrm{day}] \\
\text { Treatment group }\end{array}$} \\
\hline & Treatment group & Control group & \\
\hline Baseline & $13.72 \pm 2.29^{*}$ & $7.09 \pm 1.23$ & $12.5 \pm 0.0$ \\
\hline 1 month & $7.71 \pm 2.36^{\#}$ & $7.02 \pm 1.24$ & $23.2 \pm 5.2$ \\
\hline 2 months & $5.22 \pm 1.48^{\star \#}$ & $7.16 \pm 1.23$ & $24.5 \pm 6.1$ \\
\hline 3 months & $4.60 \pm 1.24^{\star \#}$ & $7.65 \pm 1.36$ & $25.5 \pm 6.1$ \\
\hline 6 months & $4.21 \pm 0.78^{\star \#}$ & $7.89 \pm 1.32$ & $25.7 \pm 7.6^{+}$ \\
\hline 12 months & $4.18 \pm 0.71^{\text {*\# }}$ & $8.05 \pm 1.37$ & $26.3 \pm 7.3$ \\
\hline 18 months & $4.14 \pm 0.77^{\star \#}$ & $8.15 \pm 1.53$ & $26.8 \pm 9.1$ \\
\hline 24 months & $4.15 \pm 0.82^{\star \#}$ & $8.29 \pm 1.50$ & $27.3 \pm 9.9$ \\
\hline 30 months & $4.08 \pm 0.64^{\star \#}$ & $8.30 \pm 1.38$ & $28.0 \pm 9.9$ \\
\hline 36 months & $4.10 \pm 0.62^{\star \#}$ & $8.35 \pm 1.45$ & $28.0 \pm 9.9$ \\
\hline
\end{tabular}

Data are presented as mean $\pm S D .{ }^{*} P<0.001 \mathrm{vs}$. control group; ${ }^{\#} P<0.001 \mathrm{vs}$. baseline. ${ }^{+}$The dose was decreased in two patients because of angina. 
Table III. Changes of SCr and eGFR in the two groups

\begin{tabular}{|lcccc|}
\hline \multirow{2}{*}{ Time } & \multicolumn{2}{c}{$\mathrm{SCr}[\mathrm{mg} / \mathrm{dl}]$} & \multicolumn{2}{c|}{ eGFR $\left[\mathrm{ml} / \mathrm{min} / 1.73 \mathrm{~m}^{2}\right]$} \\
\cline { 2 - 5 } & Treatment group & Controlgroup & Treatment group & Control group \\
\hline Baseline & $136.8 \pm 25.5$ & $136.1 \pm 23.7$ & $43.4 \pm 6.1$ & $42.8 \pm 5.9$ \\
\hline 1 month & $123.4 \pm 19.9^{\#}$ & $137.6 \pm 23.5$ & $46.7 \pm 5.0$ & $42.3 \pm 6.0$ \\
\hline 2 months & $120.5 \pm 21.2^{\text {*\# }}$ & $139.8 \pm 24.5$ & $47.9 \pm 4.8$ & $41.9 \pm 6.0$ \\
\hline 3 months & $118.7 \pm 20.0^{\text {*\# }}$ & $141.3 \pm 25.3$ & $49.3 \pm 4.9$ & $41.4 \pm 5.8$ \\
\hline 6 months & $120.6 \pm 19.6^{* \#}$ & $142.8 \pm 25.4$ & $49.6 \pm 5.3$ & $39.6 \pm 5.7$ \\
\hline 12 months & $122.5 \pm 20.2^{\text {*\# }}$ & $144.0 \pm 26.3$ & $47.1 \pm 5.0$ & $38.2 \pm 5.5$ \\
\hline 18 months & $123.3 \pm 18.9^{\text {*\# }}$ & $145.6 \pm 26.5$ & $46.1 \pm 5.0$ & $37.7 \pm 5.5$ \\
\hline 24 months & $124.0 \pm 19.0^{\text {*\# }}$ & $145.3 \pm 25.8$ & $46.0 \pm 4.6$ & $37.2 \pm 5.4$ \\
\hline 30 months & $124.9 \pm 19.8^{* \#}$ & $145.8 \pm 25.8$ & $45.8 \pm 4.7$ & $36.2 \pm 5.2$ \\
\hline 36 months & $126.0 \pm 19.7^{\text {*\# }}$ & $146.2 \pm 26.1$ & $45.8 \pm 4.8$ & $35.8 \pm 5.3$ \\
\hline F-value & $F_{\text {time }} 62.78$ & $F_{\text {group }} 52.25$ & $F_{\text {grouptime }} 62.87$ & $p<0.001$ \\
\hline
\end{tabular}

Data are presented as mean $\pm S D$. eGFR was calculated using the CKD-EPI equation. ${ }^{\star} P<0.001$ vs. control group; ${ }^{\#} P<0.001$ vs. baseline.

study; however, between 6 and 12 months, the dose was reduced from $37.5 \mu \mathrm{g} /$ day to $25.0 \mu \mathrm{g} /$ day in 2 patients because of angina pectoris.

Serum creatinine levels at various time points during the follow-up period are listed in Table III. $\mathrm{SCr}$ levels at baseline were comparable in the two groups (136.8 \pm 25.5 vs. $136.1 \pm 23.7 \mathrm{mg} / \mathrm{dl} ; p=$ 0.89). SCr levels decreased in the treatment group during the follow-up period but increased gradually in the control group. From 36 months to the end of follow-up, SCr levels were significantly different in the two groups $(126.0 \pm 19.7$ vs. $146.2 \pm 26.1 \mathrm{mg} /$ $\mathrm{dl} ; p<0.001)$.

To clarify the natural course of eGFR after THRT, a repeated measurement design analysis was performed. Table III presents the eGFR at different time points in each treatment group, and their interactions were significantly different $(p<0.001)$.

Figure 1 illustrates the changes in the eGFR from baseline to 36 months after treatment. The eGFR increased rapidly over the first 6 months, while TSH levels were declining, and then plateaued, whereas the eGFR in the control group decreased over time.

\section{Discussion}

Although the prevalence of subclinical hypothyroidism tends to increase in elderly patients, the decision to treat this condition is controversial. During the 36-month follow-up, our findings suggested that THRT for subclinical hypothyroidism preserved renal function, improved renal outcome in elderly patients, and was safe. These data are in accordance with other recent studies $[9,10]$.

We observed that the eGFR increased within 6 months after therapy, although the eGFR did

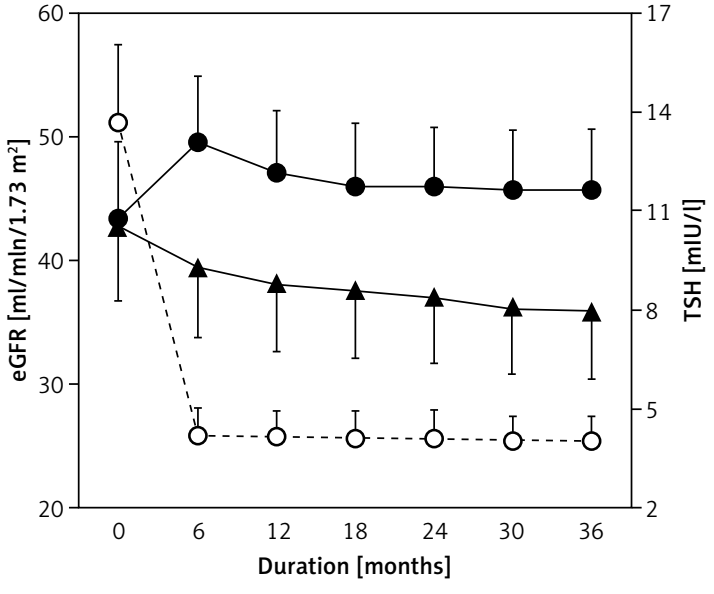

eGFR of treatment group $\quad-\quad$ eGFR of control group

- O-TSH level of treatment group

Figure 1. The eGFR in the two groups and TSH levels in the treatment group after therapy

not further improve after 6 months of longitudinal observation; there are various potential causes, including aging, that may have influenced renal dysfunction. The mechanisms of hypothyroidism-associated kidney dysfunction could explain this phenomenon. Due to the lack of thyroid hormone, decreased cardiac output and increased peripheral resistance lead to an overall decrease in systemic blood volume, thereby decreasing renal blood flow, which can decrease the eGFR [16-18]. In adult animals, hypothyroidism reduces the single nephron GFR, renal plasma flow, and glomerular transcapillary hydrostatic pressure [19, 20]. Isotopic renal function studies have demonstrated that the hemodynamic changes associated with severe hypothyroidism primarily affect glomerular 
function [21]. Therefore, after THRT, cardiac output and myocardial contractility recover to physiological values, leading to increased renal plasma flow and creatinine clearance $[22,23]$. This indicates that renal dysfunction is predominantly caused by functional changes rather than by permanent histological damage.

Thyroid substitution could prevent progression to overt hypothyroidism, improve cognitive dysfunction [24], and minimize the deleterious effects on cardiovascular function and lipid levels. However, treatment may also elicit adverse effects, such as nervousness, palpitations, atrial fibrillation, and exacerbated angina pectoris. Some endocrinologists dictate that treatment is indicated in patients with a mild TSH increase and certain risk factors $[25,26]$, whereas others believe that treatment is seldom necessary; these endocrinologists posit that subclinical hypothyroidism exerts a protective effect in geriatric patients that has been attributed to a lower metabolic rate $[14,27,28]$.

Most professional organizations advocate starting replacement therapy in elderly patients with TSH concentrations greater than $10 \mathrm{mIU} /$, those with antithyroid antibodies, and symptomatic elderly patients with TSH levels between 4.5 and $10 \mathrm{mIU} / \mathrm{l}$. A reasonable target TSH level is 3-4 $\mathrm{mIU} / \mathrm{l}$ in individuals between 60 and 75 years old and 4-6 mIU/l in individuals older than 75 years $[13,14]$. Over a 13-year period, the study found no association between new or persistent TPOAb positivity and death in the oldest old [11], so the treatment of patients with no symptoms, a normal TSH level and only slightly increased TPOAb values seems unnecessary. Therefore, we formed treatment and control groups based on the above principles, and all of the patients were elderly with overall good health. To avoid physiological renal function decline with aging, we selected patients with mild/moderate renal failure, excluded patients with advanced kidney disease, and included a control group with similar age. Compared with the control group, the eGFR of the treatment group significantly improved after THRT. Moreover, the protective effect on renal function could be long-lasting.

In our study, the average final dose in the treatment group was $28.0 \mu \mathrm{g} /$ day, which was significantly lower than that in other studies $(46.0 \mu \mathrm{g} /$ day or $65 \mu \mathrm{g} /$ day) $[10,29]$. Low doses are often adequate in elderly patients because of decreased T4 metabolism. During our follow-up, the dose was reduced in 2 patients because of exacerbated angina pectoris, but no patients withdrew from the study. These observations indicated that THRT is safe when obeying the following principles: 1) start with a low dose; 2) adjust the dose slowly; and 3) perform careful follow-up to prevent overtreat- ment. Personalized treatment should be undertaken knowing the rates of related complications.

There were some limitations of this study. First, it was not a randomized trial: we grouped the patients according to specific standards and physician experience, not in a random manner, which may introduce bias. However, all of the patients were generally healthy overall and the eGFR at baseline was comparable in the two groups. Second, as in many other studies, we used creatinine-based estimates of the GFR; however, changes in serum creatinine levels in patients with thyroid disorders reflect actual changes in the GFR [30]. The CKD-EPI equation can more accurately categorize the risk for mortality and end-stage renal disease in elderly Asian patients [31]. Third, this study had a small sample size and was conducted in a Chinese city which is considered to be an iodine-sufficient area; therefore, the results may not be applicable to other populations.

In conclusion, abnormal thyroid function and CKD frequently co-exist, and TSH levels may be considered a risk factor for CKD progression in elderly patients. THRT preserves renal function, and appropriate individual treatment should be considered in elderly patients with subclinical hypothyroidism.

\section{Acknowledgments}

The authors wish to thank the staff who greatly helped us to complete the project. In addition, we appreciate all the people who contributed to this study.

\section{Conflict of interest}

The authors declare no conflict of interest.

\section{References}

1. Cappola AR, Fried LP, Arnold AM, et al. Thyroid status, cardiovascular risk, and mortality in older adults. JAMA 2006; 295: 1033-41.

2. Gopinath B, Harris DC, Wall JR, Kifley A, Mitchell P. Relationship between thyroid dysfunction and chronic kidney disease in community-dwelling older adults. Maturitas 2013; 75: 159-64.

3. Chonchol M, Lippi G, Salvagno G, Zoppini G, Muggeo M, Targher G. Prevalence of subclinical hypothyroidism in patients with chronic kidney disease. Clin J Am Soc Nephrol 2008; 3: 1296-300.

4. Verhelst J, Berwaerts J, Marescau B, et al. Serum creatine, creatinine, and other guanidino compounds in patients with thyroid dysfunction. Metabolism 1997; 46: 1063-7.

5. Hollander JG, Wulkan RW, Mantel MJ, Berghout A. Correlation between severity of thyroid dysfunction and renal function. Clin Endocrinol (Oxf) 2005; 62: 423-7.

6. Asvold BO, Bjoro T, Vatten LJ. Association of thyroid function with estimated glomerular filtration rate in 
a population-based study: the HUNT study. Eur J Endocrinol 2011; 164: 101-5.

7. Adrees M, Gibney J, El Saeity N, Boran G. Effects of 18 months of L-T4 replacement in women with subclinical hypothyroidism. Clin Endocrinol 2009; 71: 298-303.

8. Kreisman SH, Hennessey JV. Consistent reversible elevations of serum creatinine levels in severe hypothyroidism. Arch Intern Med 1998; 159: 79-82.

9. Shin DH, Lee MJ, Kim SJ, et al. Preservation of renal func tion by thyroid hormone replacement therapy in chronic kidney disease patients with subclinical hypothyroid ism. J Clin Endocrinol Metab 2012; 97: 2732-40.

10. Shin DH, Lee MJ, Lee HS, et al. Thyroid hormone replacement therapy attenuates the decline of renal function in chronic kidney disease patients with subclinical hypothyroidism. Thyroid 2013; 23: 654-61.

11. Waring AC, Arnold AM, Newman AB, Buzkova P, Hirsch C, Cappola AR. Longitudinal changes in thyroid function in the oldest old and survival: the Cardiovascular Health Study All-Stars Study. J Clin Endocrinol Metab 2012; 97: 3944-50.

12. van den Beld AW, Visser TJ, Feelders RA, Grobbee DE, Lamberts SW. Thyroid hormone concentrations, disease, physical function, and mortality in elderly men. J Clin Endocrinol Metab 2005; 90: 6403-9.

13. Gharib H, Tuttle RM, Baskin HJ, Fish LH, Singer PA, McDermott MT. Consensus Statement \#1: Subclinical thyroid dysfunction: a joint statement on management from the American Association of Clinical Endocrinologists, the American Thyroid Association, and The Endocrine Society. J Clin Endocrinol Metab 2005; 90: 581-5.

14. Surks MI, Ortiz E, Daniels GH, et al. Subclinical thyroid disease-scientific review and guidelines for diagnosis and management. JAMA 2004; 291: 228-38.

15. Levey AS, Stevens LA, Schmid CH, et al. A new equation to estimate glomerular filtration rate. Ann Intern Med 2009; 150: 604-12.

16. Toft AD, Boon NA. Thyroid disease and the heart. Heart 2000; 84: 455-60.

17. Chonchol M, Lippi G, Salvagno G, Zoppini G, Muggeo M, Targher G. Prevalence of subclinical hypothyroidism in patients with chronic kidney disease. Clin J Am Soc Nephrol 2008; 3: 1296-300.

18. Klein I, Danzi S. Thyroid disease and the heart. Circulation 2007; 116: 1725-35.

19. Falk SA, Buric V, Hammond WS, Conger JD. Serial glomerular and tubular dynamics in thyroidectomized rats with remnant kidneys. Am J Kidney Dis 1991; 17: 218-27.

20. Bradley SE, Stéphan F, Coelho JB, Réville P. The thyroid and the kidney. Kidney Int 1974; 6: 346-65.

21. Karanikas G, Schütz M, Szabo M, et al. Isotopic renal function studies in severe hypothyroidism and after thyroid hormone replacement therapy. Am J Nephrol 2004; 24: 41-5.

22. Capasso G, De Tommaso G, Pica A, et al. Effects of thyroid hormones on heart and kidney functions. Miner Electrolyte Metab 1999; 25: 56-64.

23. Villabona C, Sahun M, Roca M, et al. Blood volumes and renal function in overt and subclinical primary hypothyroidism. Am J Med Sci 1999; 318: 277-80.

24. Aghili R, Khamseh ME, Malek M, et al. Changes of subtests of Wechsler Memory Scale and cognitive function in subjects with subclinical hypothyroidism following treatment with levothyroxine. Arch Med Sci 2012; 8: 1096-101.

25. McDermott MT, Ridgway EC. Subclinical hypothyroidism is mild thyroid failure and should be treated. J Clin Endocrinol Metab 2001; 86: 4585-90.
26. Biondi B, Lombardi G, Palmieri EA. Screening and treatment for subclinical thyroid disease. JAMA 2004; 291: 1562; author reply, 1562-3.

27. Chu JW, Crapo LM. The treatment of subclinical hypothyroidism is seldom necessary. J Clin Endocrinol Metab 2001; 86: 4591-9.

28. Gussekloo J, van Exel E, de Craen AJ, Meinders AE, Frolich M, Westendorp RG. Thyroid status, disability and cognitive function, and survival in old age. JAMA 2004; 292: 2591-9.

29. Caraccio N, Natali A, Sironi A, et al. Muscle metabolism and exercise tolerance in subclinical hypothyroidism: a controlled trial of levothyroxine. J Clin Endocrinol Metab 2005; 90: 4057-62.

30. Karanikas G, Schütz M, Szabo M, et al. Isotopic renal function studies in severe hypothyroidism and after thyroid hormone replacement therapy. Am J Nephrol 2004; 24: 41-5.

31. Matsushita K, Mahmoodi BK, Woodward M, et al. Comparison of risk prediction using the CKD-EPI equation and the MDRD study equation for estimated glomerular filtration rate. JAMA 2012; 307: 1941-51. 